\title{
La evolución de destinos turísticos litorales consolidados. Análisis comparado de Balneario Camboriú (Brasil) y Benidorm (España) ${ }^{1}$
}

\author{
Jennifer Caroline SOARES \\ Fundación CAPES (Ministerio de Educación de Brasil) \\ Instituto Universitario de Investigaciones Turísticas \\ Universidad de Alicante \\ jenni_caroline@yahoo.com.br \\ Josep Antoni IVARs BAIDAL \\ Universidad de Alicante \\ josep.ivars@ua.es \\ José Manoel GÂNDARA \\ Universidad Federal do Paraná \\ jmggandara@yahoo.com.br
}

Recibido: 3 de octubre del 2014

Enviado a evaluar: 18 de octubre del 2014

Aceptado: 14 de septiembre del 2015

\section{RESUMEN}

El objetivo de este trabajo consiste en estudiar la evolución de los destinos turísticos litorales consolidados a partir del análisis comparado entre Balneario Camboriú y Benidorm. Se trata de dos destinos localizados en contextos territoriales y turísticos diferentes, en los que se contrastan de manera empírica los indicadores de evolución de los destinos y se vinculan las dinámicas evolutivas con el modelo territorial-turístico resultante en cada destino. El análisis realizado permite contrastar los postulados de los modelos evolutivos clásicos (Butler, 1980) e incorporar los nuevos planteamientos de la geografía económica evolutiva. La investigación delimita cronológicamente los periodos de desarrollo de ambos destinos para identificar los factores con mayor incidencia en la evolución de los mismos. Una evolución marcada, fundamentalmente, por la ubicación geográfica, la planificación y gestión urbanoturística a diferentes escalas, la dependencia de determinados mercados emisores y la influencia de

${ }^{1}$ Este artículo deriva de los trabajos realizados para la tesis doctoral de Jennifer Caroline Soares "La evolución de los destinos turísticos litorales consolidados. Un análisis comparado de Balneario Camboriú (Brasil) y Benidorm (España)” defendida en el Instituto Universitario de Investigaciones Turísticas de la Universidad de Alicante. Dicha investigación se ha realizado con el apoyo de la Beca de Doctorado concedida por el Instituto Turismo de España - Turespaña. 
factores macroeconómicos. Un conjunto de factores interrelacionados que dibujan trayectorias dispares para los destinos analizados.

Palabras clave: ciclo de vida, destinos litorales, geografía económica evolutiva, Balneário Camboriú, Benidorm.

\title{
The evolution of consolidated coastal tourist destinations. Comparative analysis of Balneario Camboriu (Brazil) and Benidorm (Spain)
}

\begin{abstract}
The aim of this work is to study the evolution of coastal tourist destinations consolidated from a compared analysis between Balneario Camboriu y Benidorm. These two destinations located in different territorial and touristic contexts, in which are contrasted empirically indicators of destinations evolution and evolutionary dynamics are linked to the resulting land-tourism model in each destination. The analysis allows us to contrast the tenets of classical evolutionary models (Butler, 1980) and incorporate the new approaches of evolutionary economic geography. Research defines the chronological periods of development of both locations to identify factors with the greatest impact on their evolution. An evolution marked mainly by geographical location, urban and tourism planning and management at different scales, the dependence of certain source markets and the influence of macroeconomic factors. A set of interrelated factors that draw disparate paths to the destinations analyzed.
\end{abstract}

Key words: Lifecycle, coastal destination, Evolutionary Economic Geography, Balneário Camboriú, Benidorm.

\section{L'évolution des destinations côtières consolidés touristiques. Analyse comparative de Balneario Camboriu (Brésil) et Benidorm (Espagne)}

\section{RÉSUMÉ}

L'objectif de ce travail consiste à étudier l'évolution des destinations touristiques des littoraux consolidés à partir de l'analyse comparée entre Balneario Camboriu et Benidorm. Il s'agit de deux destinations localisées dans des contextes territoriaux et touristiques différents, dans lesquelles on contraste d'une manière empirique les indicateurs d'évolution des destinations et les dynamiques évolutives sont liées avec le modèle territorial - touristique résultant dans chaque destination. L'analyse réalisée permet contraster les facteurs des modèles évolutifs classiques (Butler, 1980) et incorporer les nouveaux approches de la géographie économique évolutive. La recherche délimite chronologiquement les périodes de développement des deux destinations pour identifier les facteurs avec la plus grande importance. Une évolution marquée, fondamentalement, par la situation géographique, la planification et la gestion urbaine - touristique à différentes échelles, la dépendance des principaux marchés émetteurs et l'influence de facteurs macroéconomiques. Un assemblage de facteurs mis en relation qui dessine des trajectoires différentes pour les destinations analysées.

Mots clés: cycle de vie, destinations touristiques des littoraux, géographie économique évolutive, Balneario Camboriú, Benidorm. 


\section{INTRODUCCIÓN}

El turismo denominado de sol y playa es el segmento que genera el mayor flujo de turistas a escala internacional (Ayala et al., 2003; Vera Rebollo et al., 2011), dentro de unos esquemas de producción y consumo asociados tradicionalmente a modelos fordistas (Torres, 2002; Shaw y Williams, 1996; Urry, 1990). A pesar de mantener el liderazgo en cuanto a la atracción de visitantes, la dinámica del turismo de sol y playa presenta cambios estructurales impulsados por factores diversos como el impacto de las nuevas tecnologías, los cambios en las motivaciones y el comportamiento de la demanda, el incremento de los destinos competido o la aparición de nuevos modelos de negocio empresarial.

Estas dinámicas favorecen un nuevo escenario de viajes más personalizados, con mayor diversidad motivacional y una creciente segmentación de la demanda que provoca ofertas más especializadas (turismo cultural, activo, enoturismo, etc.), asociadas a un modelo postfordista (Donaire, 1998). No obstante, aunque se constatan cambios evidentes, como la disminución de la contratación de paquetes turísticos y el aumento del uso de internet, la preferencia por el turismo de sol y playa se mantiene, provocando la aparición de dinámicas neofordistas (Ioannides y Debbage, 1998).

Lógicamente, la evolución de los destinos turísticos litorales se ha visto afectada por estas transformaciones. Estos destinos se han caracterizado, en general, por un elevado dinamismo desde el punto de vista turístico, urbanístico y demográfico. Los modelos teóricos evolutivos, como el de Miossec (1977) o Butler (1980) inciden en este dinamismo y en el riesgo de que un excesivo crecimiento supere la capacidad de carga del destino y origine su declive. La evolución de los destinos turísticos ha sido objeto de análisis en múltiples estudios de caso, en buena parte compilados en Butler (2006a, 2006b), desde la perspectiva de la teoría del ciclo de vida del destino turístico (CVDT) del mismo autor. Por otra parte, nuevos enfoques como Geografía Económica Evolutiva (EEG, acrónimo en inglés) plantean un marco interpretativo más complejo y abren nuevas vías de trabajo en torno a la evolución de los espacios turísticos.

Los estudios de caso son abundantes, sin embargo, son más escasos los análisis comparados a escala local, en contextos territoriales y socioeconómicos distintos, donde las dinámicas internas de los destinos responden a condiciones locales propias que interactúan con factores externos derivados de la globalización de la actividad turística de manera distinta (Agarwal, 2005). El análisis de esta interacción, en contextos territoriales y turísticos diferentes, que participan de manera desigual de las dinámicas de la globalización, aporta nuevas evidencias desde el punto de vista de los modelos evolutivos teóricos y de la planificación y gestión de los destinos turísticos consolidados.

Los dos municipios seleccionados, Balneario Camboriú y Benidorm, figuran entre los principales destinos de turistas nacionales y extranjeros en sus respectivos países, cuentan con una importante concentración de oferta de alojamiento y se caracterizan por una economía centrada en el sector de servicios y por atraer un tipo de demanda de sol y playa masivo. Se trata de destinos consolidados que también presentan 
algunas similitudes en cuanto al modelo urbano; la concentración de la demanda extranjera en un mercado emisor, y el desarrollo de medidas para diversificar la oferta de sol y playa con la creación de nuevas ofertas para rejuvenecer el destino.

\section{OBJETIVOS Y METODOLOGÍA}

El objetivo general de este trabajo es estudiar la evolución de los destinos turísticos litorales consolidados a partir del análisis comparado entre Balneario Camboriú y Benidorm, con dos objetivos específicos fundamentales: identificar las diferentes fases de su evolución y los procesos más relevantes de la misma mediante el análisis de los indicadores turísticos más significativos y proponer aspectos de mejora en la planificación y gestión de los destinos. En consecuencia, este trabajo pretende contribuir a enriquecer los fundamentos teóricos de la evolución de los espacios turísticos $\mathrm{y}$, desde una perspectiva aplicada, a favorecer nuevos planteamientos de gestión en destinos litorales consolidados.

La metodología utilizada parte de la revisión bibliográfica para analizar los procesos de evolución de los destinos litorales e identificar las variables que permiten medir dicha evolución. Una vez identificados los indicadores, se ha procedido a la recopilación de datos a través de fuentes diversas, preferentemente oficiales. En dicha etapa se han apreciado serias limitaciones estadísticas, sobre todo en el caso de Balneario Camboriú. También hay que considerar las diferencias entre las operaciones estadísticas de ambos destinos y los cambios metodológicos a lo largo de las series temporales, cuestiones que han sido consideradas a la hora de realizar el análisis.

El análisis diacrónico de los indicadores turísticos se combina con sus repercusiones respecto a la ocupación del suelo y la localización de las actividades turísticas con la finalidad de superar el insuficiente tratamiento de la dimensión territorial en los estudios evolutivos de los destinos turísticos que destacan Hall y Page (2009) desde la óptica de la geografía del turismo.

\section{EL MARCO TEÓRICO DE LA EVOLUCIÓN DE LOS DESTINOS: DE LOS MODELOS TRADICIONALES A LOS NUEVOS PLANTEAMIENTOS DE LA GEOGRAFÍA ECONÓMICA EVOLUTIVA}

Los cambios estructurales en la dinámica del turismo de sol y playa, así como las transformaciones en el comportamiento de la demanda generan alteraciones en los modelos de producción y consumo. Se observa la búsqueda de una mayor cualificación y diferenciación de los destinos, como también la orientación, al menos en teoría, hacia un desarrollo turístico sostenible. El modelo de Butler (1980) considera las atracciones turísticas finitas y los recursos no necesariamente renovables. Según este modelo, el más citado en la investigación turística internacional (Gibson, 2008), la superación de la capacidad de carga y los impactos generados conllevarían el declive de los destinos turísticos. Más de treinta años 
después de su publicación el modelo aún genera polémica sobre sus fundamentos teóricos y posibilidades de aplicación.

A pesar de las dificultades y limitaciones, muchos autores consideran que el modelo de Butler es un marco teórico útil para el análisis (Hovinen, 2002; Douglas, 1997; Tooman, 1997), y una base conceptual apta para la comparación entre destinos (Hovinen, 2002). Sin embargo, el modelo presenta dos tipos de debilidades: las dificultades de aplicación práctica y las controversias de carácter teórico-conceptual. Desde el punto de vista de su aplicación, puede citarse la falta de datos del número de turistas; la dificultad de distinguir las distintas fases del ciclo de vida; o las desviaciones en la curva de crecimiento del número de turistas (Agarwal, 1997; Haywood, 1986 apud Lagiewski, 2006; Hovinen, 2002; Cooper, 1994). Desde la óptica teórico-conceptual, el modelo atribuye los cambios en las fases de ciclo de vida y el supuesto declive, principalmente, a un número limitado de factores internos, sin considerar significativos factores externos como por ejemplo, las crisis políticas y económicas. Además el modelo no considera los esfuerzos continuos de reestructuración (Agarwal, 1994). De esta forma el CVDT no posibilita una total comprensión de las dinámicas que se están llevando a cabo en los destinos.

Johnston (2001) sugiere que el análisis del ciclo de vida de los destinos requiere la identificación de los mecanismos de cambio (los puntos de ruptura que conducen a la siguiente etapa, que pueden ocurrir rápidamente -eventos críticos- o lentamente transiciones borrosas). De acuerdo con estos planteamientos, cabe mencionar la aportación reciente de Butler $(2011 ; 2012)$, que considera que los destinos se ven afectados por factores externos (actitudes, tecnología, política y economía) que muchas veces son los que generan el dinamismo, como también por factores internos (hábitos, gustos, preferencias e inversiones) que provocan la "inercia". Son los agentes del destino los que provocan los efectos locales (renovación/rejuvenecimiento, diversificación de la oferta, singularización, etc.), mientras que los agentes externos (entorno político, económico, mediático o fenómenos como el cambio climático) configuran el marco global en el que operan los destinos (Butler, 2011). Soares et al. (2012) han recopilado indicadores a partir de la teoría de Butler y sus numerosas aplicaciones, y han propuesto un marco de análisis para posibilitar el análisis del ciclo de vida de los destinos turísticos litorales atendiendo a la singularidad de cada destino.

En la extensa producción científica acerca de la evolución de los destinos turísticos litorales se observa una amplia variedad de factores de influencia derivados de dinámicas internas y externas. Respecto a las primeras, cabe destacar las más recurrentes, tales como: la actuación de los intermediarios (Marrero Rodríguez y Santana Turégano, 2008; Knowles y Curtis, 1999; Ioannides, 1992; Debbage, 1990; Oglethorpe, 1984 apud Lagiewski 2006); el desarrollo del turismo residencial (Virgen Aguilar, 2009; Priestley y Mundet, 1998; Strapp, 1988); el deterioro ambiental (Aguiló et al., 2005; Priestley y Mundet, 1998); los tipos de turistas que frecuentan el destino (Marrero Rodríguez y Santana Turégano, 2008; Wilkinson, 1996); la dependencia de un determinado mercado emisor (Marrero Rodríguez y Santana Turégano, 2008; Moore y Whitehall, 2005; Cooper y Jackson, 1989 apud Butler 2006a); las acciones del poder público (Virgen Aguilar, 2009; Oreja Rodríguez et al., 
2008; Weaver, 2000; Douglas, 1997; Ioannides, 1992; Cooper y Jackson, 1989 apud Butler 2006a); la planificación (Corak, 2006; Knowles y Curtis, 1999; Weaver, 1992, 1990 y 1988 apud Lagiewski 2006 ); las medidas de rejuvenecimiento (Corak, 2006; Knowles y Curtis, 1999; Agarwal, 1997; Choy, 1992) y la competitividad del destino (Priestley y Mundet, 1998; Claver-Cortés et al., 2007; Choy, 1992).

Entre los factores externos destacan: los cambios en los consumidores (gustos/comportamientos) (Virgen Aguilar, 2009; Aguiló et al., 2005; Lundtorp y Vanhill, 2001); el aumento de la competencia entre destinos (Agarwal, 2002; Lundtorp y Vanhill, 2001); la devaluación de la moneda (Lundtorp y Vanhill, 2001; Priestley y Mundet, 1998); las crisis económicas internacionales (Virgen Aguilar, 2009; Choy, 1992); las inestabilidades políticas (Choy, 1992) y los conflictos bélicos (Corak, 2006; Lundtorp y Vanhill, 2001; Douglas, 1997).

Por último, hay que hacer referencia a las aportaciones recientes que han destacado la importancia del análisis del desarrollo de los destinos turísticos desde una perspectiva evolutiva, inspirada en la Geografía Económica Evolutiva, la cual se centra en los procesos que transforman la organización espacial de la producción, la distribución y el consumo desde dentro del sistema económico a través del tiempo (Boschma y Martin, 2006; 2010). Trabajos recientes (Brouder y Eriksson, 2013; Ma y Hassink; 2013; Sanz y Anton, 2014) consideran que la EEG complementa el modelo del ciclo de vida de los destinos turísticos y contribuye a paliar sus limitaciones. De acuerdo con estos trabajos, los fundamentos epistemológicos de la EEG se basan en el darwinismo generalizado (a partir de conceptos como variedad, selección, coevolución y continuidad), la teoría de la complejidad y la dependencia del camino (path dependence).

Ma y Hassink (2013) han aplicado la teoría de la dependencia del camino, y de la coevolución a la Gold Coast australiana. La dependencia del camino explica la evolución del destino a partir de decisiones pasadas que describen una trayectoria evolutiva dependiente, que puede romperse mediante la creación de nuevos caminos (path creation). Este planteamiento refuerza la perspectiva histórica y la dependencia del contexto territorial (place dependent processes) (Martin y Sunley, 2006). Las teorías de la coevolución se basan en la interdependencia mutua de los agentes del sistema económico en dos planos interrelacionados (micro y macro escala), un enfoque que remarca la complejidad y heterogeneidad del destino turístico y de sus relaciones con el entorno socioeconómico. De este modo, la evolución futura de la Gold Coast australiana dependerá de la interacción entre los cambios estructurales globales y el comportamiento de los agentes del destino, públicos y privados.

De acuerdo con estos planteamientos, la evolución del destino deja de explicarse exclusivamente por la curva determinada por una variable (número de turistas, generalmente) del CVDT para convertirse en un proceso abierto en el que caben diferentes trayectorias evolutivas de acuerdo con las decisiones pasadas, la interacción de los agentes y la dialéctica local-global.

En este proceso de búsqueda de un marco teórico mejor adaptado a la complejidad de la evolución de los destinos, la singularidad del presente trabajo radica en el análisis comparado de dos destinos en contextos territoriales y turísticos diferentes, en 
los que se contrastan de manera empírica los indicadores de evolución de los destinos y se vinculan las dinámicas evolutivas con el modelo territorial-turístico resultante de cada destino.

\section{CONTEXTUALIZACIÓN Y CARACTERIZACIÓN DE LOS DESTINOS ANALIZADOS}

Brasil y España son dos países con tradición turística litoral y, salvando las diferencias de superficie y localización geográfica, con un gran patrimonio turístico, tanto de carácter natural como cultural. En el panorama internacional, Brasil es un país emergente con enorme potencial y España un destino maduro, entre los principales receptores de turismo de sol y playa internacional. En 2012, Brasil, dentro de un ciclo de crecimiento económico, recibió 5,7 millones de turistas, un 0,5\% del movimiento de turismo internacional (WTO, 2013). Sin embargo, se trata de un país que se encuentra en proceso de estructuración de las bases de planificación y gestión de la actividad turística y todavía presenta deficiencias de infraestructuras básicas y de transporte. Además, la lejanía de los principales mercados emisores influye en la llegada de turistas internacionales.

Figura 1. Localización de Balneario Camboriú (Brasil) y Benidorm (España).

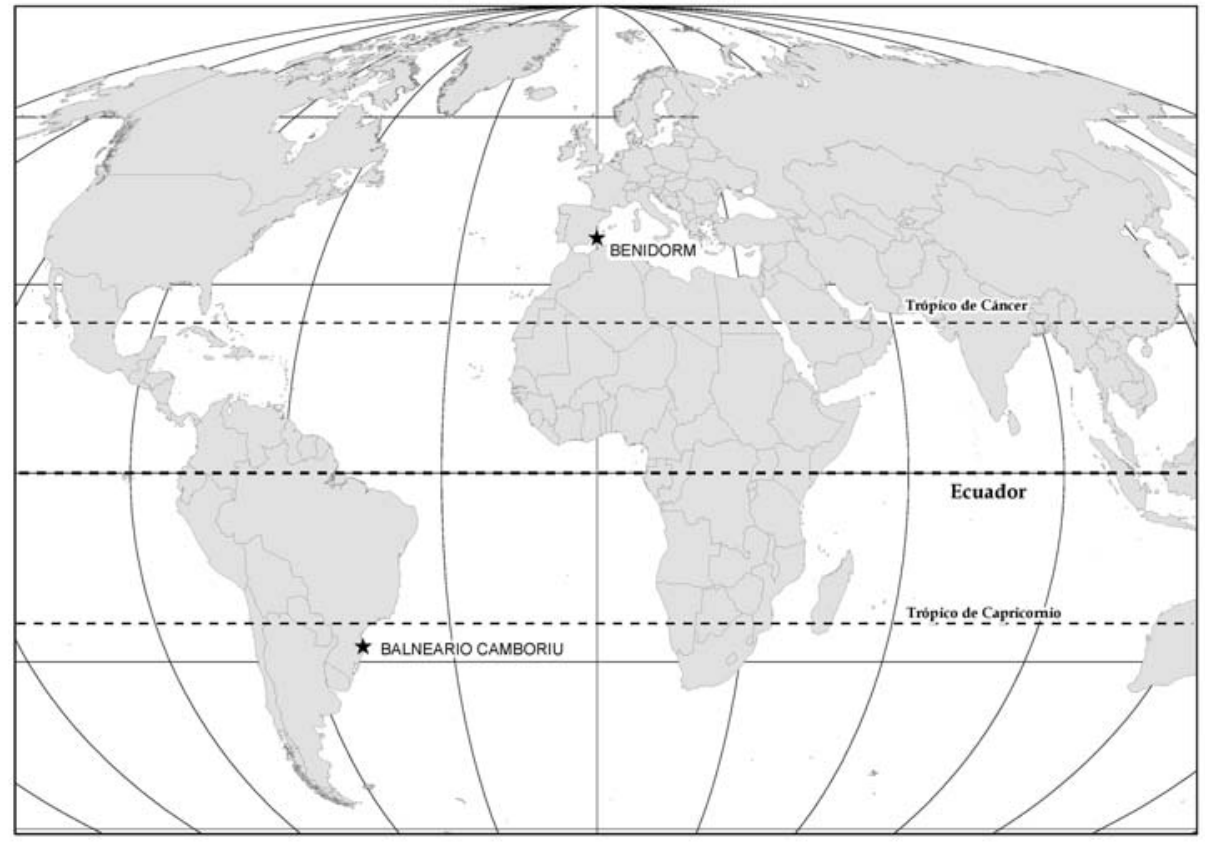

Fuente: Elaboración propia. 
España recibió en 2012, a pesar de la coyuntura de crisis económica en Europa, 57,7 millones de turistas internacionales, un 5,7\% del turismo mundial (WTO, 2013). Este país ha disfrutado históricamente de ventajas comparativas en el contexto europeo: proximidad a mercados emisores, recursos geoturísticos (clima y playas, fundamentalmente) y precios relativamente bajos. Sin embargo, la evolución socioeconómica del país y la integración en la Unión Europea han erosionado la ventaja en precios y exigen otras vías para la competitividad como la relación calidadprecio y, más recientemente, la innovación. Los destinos de sol y playa han crecido de manera paralela al turismo de masas en Europa y presentan síntomas de madurez frente a los nuevos destinos litorales competidores, tanto del Mediterráneo como del Caribe y de otros ámbitos geográficos, a pesar de que los efectos de la Primavera Árabe (2010) y la inestabilidad política del Norte de África han supuesto un desvío de turistas hacia España.

\subsection{BALNEARIO CAMBORIÚ: DEL VERANEO TRADICIONAL A LA EXPANSIÓN INMOBILIARIA EN EL CONO SUR AMERICANO}

Balneario Camboriú se localiza al sur de Brasil ( $26^{\circ} 59^{\prime} \mathrm{S}$ y $48^{\circ} 38^{\prime} \mathrm{W}$ ), en la microrregión de la $\mathrm{Foz}$ (desembocadura) del río Itajaí. El municipio posee una extensión territorial de $46 \mathrm{Km}^{2}$ y se encuentra ubicado en el norte del litoral del Estado de Santa Catarina. Se localiza a 80 kilómetros al norte de la capital del Estado, Florianópolis. Balneario Camboriú, antes del desarrollo turístico, centraba su economía en la pesca y la agricultura. El desarrollo turístico se ha basado en el turismo de sol y playa, fundamentalmente en los meses de verano del hemisferio Sur. Balneario Camboriú pertenece al bioma de la Mata Atlántica y posee un clima más benigno que otras regiones del sur de Brasil, con las cuatro estaciones diferenciadas y elevadas tasas de precipitación. El desarrollo turístico se ha centrado en la Playa Central, la mayor y más urbanizada. Posee otras nueve playas, cinco de las cuales se encuentran menos antropizadas, las denominadas Playas Agrestes, ubicadas al sur del municipio.

Los inicios de la actividad turística en Balneario Camboriú se remontan a 1926, con la construcción de casas de verano por los germano-brasileños que residían en el Valle del Itajaí (Borba Corrêa, 1985). De manera paralela a la construcción de residencias, también se ha observado la progresiva creación de establecimientos hoteleros de carácter familiar. Existen registros de que dos de los primeros hoteles eran considerados de elevada categoría en la época. El periodo comprendido entre la mitad de los años cuarenta y aproximadamente los inicios de los años setenta, se caracteriza por la construcción del trazado urbano de la ciudad, mediante numerosas parcelaciones definidas por la iniciativa privada y realizadas a partir de estructura de las propiedades agrícolas existentes (Skalee y Reis, 2008). Como consecuencia de este proceso, no se tuvo en consideración la proximidad de las construcciones a la playa y la preservación de espacios públicos, lo que derivó en problemas en la configuración del trazado de las calles y en la ausencia de áreas verdes. Además, las 
construcciones se caracterizaron por la elevada densidad de ocupación de las parcelas (Danielsky, 2009).

En la década de 1970 los flujos de turistas se vieron intensificados debido a la construcción de la autopista BR101 que conecta Brasil de norte a sur por la costa. Balneario Camboriú se transformó en un importante destino turístico nacional y uno de los principales destinos turísticos de los turistas argentinos que visitan Brasil. Sin embargo, el proceso de evolución de Balneario Camboriú no fue acompañado por una legislación relativa a la ordenación del territorio eficiente y tampoco por un crecimiento de las infraestructuras, principalmente las relacionadas al saneamiento básico. Balneario Camboriú se transformó en un destino de masas, y la falta de una planificación urbana fue determinante para la existencia de diversos problemas de movilidad urbana. De manera paralela al turismo, la construcción civil se transformó en una de las principales actividades económicas del municipio, caracterizada por una fuerte especulación inmobiliaria.

\subsection{BENIDORM: DE NÚCLEO MARINERO A OCIURBE MEDITERRÁNEA}

Benidorm, ubicado en la costa mediterránea española ( $38^{\circ} 32^{\prime} \mathrm{N}$ y $\left.0^{\circ} 08^{\prime} \mathrm{E}\right)$, posee una extensión territorial de $39 \mathrm{~km}^{2}$. El turismo en este pequeño núcleo marinero y agrícola se remonta a mediados del s. XIX cuando familias adineradas de Madrid y Alcoy comenzaron a visitarlo (Wilson, 1999). La benignidad del clima mediterráneo y la existencia de unas magníficas playas de orientación sur conforman los recursos básicos sobre los que se asienta el desarrollo turístico. Paulatinamente, se desarrollan prácticas balnearias en la playa de Levante hasta que se aprueba el Plan General de Ordenación Urbana de 1956, modificado en 1963, que sienta las bases del característico modelo urbano-turístico de la ciudad basado en la densidad edificatoria, la construcción vertical y las manzanas abiertas.

Durante los años sesenta se asiste a un notable crecimiento urbanístico, sobre todo en el ensanche de Levante. En 1967 se inaugura el aeropuerto de El Altet (Alicante) que permitirá canalizar la demanda internacional hacia Benidorm. El crecimiento de los vuelos chárter va aparejado al inicio de los contratos con turoperadores y a la construcción de hoteles, financiados, en parte, por los propios turoperadores extranjeros, fundamentalmente británicos, que necesitan capacidad hotelera para acomodar una demanda creciente. De este modo, con una estructura urbana característica, la especialización hotelera frente a la residencial de otros municipios del entorno y las relaciones con los turoperadores internacionales, Benidorm se transforma en lo que Gaviria et al. (1997) definieron como una ociurbe.

\subsection{INDICADORES BÁSICOS DE LOS DESTINOS COMPARADOS}

Con el fin de caracterizar ambos destinos, se resumen en la tabla 1, determinadas variables de oferta y demanda turística. 
Tabla 1. Caracterización de los destinos Balneario Camboriú y Benidorm.

\begin{tabular}{|c|c|c|}
\hline & Balneario Camboriú & Benidorm \\
\hline Población & 108.107 hab. (IBGE, 2010) & 71.198 hab. (INE, 2011). \\
\hline $\begin{array}{c}\text { Oferta de } \\
\text { alojamiento }\end{array}$ & $\begin{array}{l}\text { * Capacidad alojativa total } \\
\text { estimada : } 18.619 \text { en medios de } \\
\text { hospedaje reglados 93.376 en } \\
\text { viviendas de potencial uso } \\
\text { turístico. } \\
\text { * } 87 \text { hoteles (17.347 plazas), } 27 \\
\text { posadas (1.272 plazas) y } 7 \\
\text { campings (SECTURBC, 2010). } \\
\text { * Hoteles: el } 41 \% \text { se clasifican } \\
\text { como simples y el 34\% como } \\
\text { medio confort (Guía } 4 \text { Rodas, } \\
\text { 2011). } \\
\text { *a media de ocupación hotelera } \\
\text { en temporada alta fue de un } 67 \% \text {, } \\
\text { y en temporada baja fue de un } \\
\text { 38\% (SINDISOL, 2010). } \\
\text { * Posee un 83\% de las plazas } \\
\text { totales en VPUT. }\end{array}$ & $\begin{array}{l}\text { * Capacidad alojativa total estimada: } \\
69.834 \text { en medios de hospedaje reglados } \\
\text { y } 87.958,5 \text { en viviendas de potencial uso } \\
\text { turístico (VPUT). } \\
\text { * } 129 \text { hoteles ( } 39.941 \text { plazas), } 3 \text { hostales } \\
\text { (141 plazas), } 6.340 \text { apartamentos } \\
\text { turísticos (18.088 plazas), } 10 \text { campings } \\
\text { (11.275 plazas) y } 10 \text { pensiones (389 } \\
\text { plazas) (Conselleria de Turismo, 2010). } \\
\text { * Predominio de hoteles de } 3 \text { y cuatro } \\
\text { estrellas: El 50,14\% de las plazas se } \\
\text { clasifica como tres estrellas; y el } 33,20 \% \\
\text { como cuatro estrellas (Conselleria de } \\
\text { Turismo, 2010). } \\
\text { * La media de ocupación hotelera en } \\
\text { temporada alta fue de 85,16\% y en } \\
\text { temporada baja fue de un } 67,33 \% \text { (INE, } \\
\text { 2010). } \\
\text { *osee un 55,7\% de las plazas totales en } \\
\text { VPUT. }\end{array}$ \\
\hline $\begin{array}{l}\text { Estructura de } \\
\text { las empresas } \\
\text { de alojamiento }\end{array}$ & $\begin{array}{l}\text { Predominio de hoteles de gestión } \\
\text { familiar con algún pequeño grupo } \\
\text { hotelero y la presencia de un hotel } \\
\text { de cadena internacional en régimen } \\
\text { de franquicia administrado por un } \\
\text { grupo de hoteles locales. }\end{array}$ & $\begin{array}{l}\text { Predominio de hoteles familiares, grupos } \\
\text { hoteleros de dimensiones medias y } \\
\text { relativamente escasa presencia de cadenas } \\
\text { internacionales. }\end{array}$ \\
\hline Dem & $\begin{array}{l}\text { * } 817.418 \text { turistas en temporada } \\
\text { alta (enero y febrero) } \\
\text { (considerando todos los medios } \\
\text { de hospedaje, SANTUR, 2012) } \\
\text { * } 77 \% \text { de los turistas son nacionales } \\
\text { (SECTURBC, 2012) } \\
\text { * Argentina representa un 70,97\% } \\
\text { de los turistas extranjeros (datos } \\
\text { de temporada alta, SANTUR, } \\
\text { 2012). } \\
\text { * Viajes auto-organizados (100\%) } \\
\text { (SECTURBC, 2012). } \\
\text { En temporada alta un 32,79\% de } \\
\text { los turistas se hospedan en hoteles } \\
\text { * posadas (SANTUR, 2012). } \\
\text { 14,31\% visitan por primera vez el } \\
\text { destino (SECTURBC,2012) }\end{array}$ & $\begin{array}{l}\text { * } 2.109 .321 \text { viajeros anuales (hoteles, } \\
\text { apartamentos turísticos y acampamentos, } \\
\text { INE, 2012). } \\
\text { * Recibe un importante número de turistas } \\
\text { nacionales (57\%) y extranjeros (43\%) } \\
\text { (viajeros en establecimientos hoteleros, } \\
\text { INE, 2012) } \\
\text { * Reino Unido corresponde a un } 76 \% \text { de } \\
\text { los viajeros extranjeros y un } 74 \% \text { de las } \\
\text { pernoctaciones (extranjeros alojados en } \\
\text { hoteles, INE, 2012). } \\
\text { * Predominio de viajes auto-organizados y } \\
\text { un 27,5\% a través de agencias } \\
\text { (Ayuntamiento de Benidorm, 2012). } \\
\text { * Un 56,8\% de los turistas se hospedan en } \\
\text { hoteles (Ayuntamiento de Benidorm, } \\
\text { 2012). } \\
\text { 52,5\% visitan por primera vez el destino } \\
\text { (Ayuntamiento de Benidorm, 2012). }\end{array}$ \\
\hline
\end{tabular}

Fuente: Elaboración propia, a partir de las fuentes citadas. 
A partir de estos datos se constatan una serie de características básicas: la gran capacidad alojativa de ambos destinos, tanto en alojamiento reglado como residencial; una orientación a segmentos de demanda de renta media; la dependencia respecto a un mercado extranjero específico; y las diferencias en cuanto a grado de ocupación y estacionalidad, así como desde el punto de vista de la organización individual de los viajes y el porcentaje de nuevos visitantes.

\section{LA EVOLUCIÓN RECIENTE DE BALNEARIO CAMBORIÚ Y BENIDORM: IDENTIFICACIÓN DE LOS PERIODOS Y FACTORES DE CAMBIO FUNDAMENTALES}

El análisis de la evolución de ambos destinos requiere la existencia de una serie de datos consistente y que abarque un periodo de tiempo suficientemente amplio. Idealmente, las variables utilizadas deberían ser las mismas para ambos destinos pero los sistemas de información difieren de manera considerable. En el caso de Balneario Camboriú, se ha utilizado como referencia la evolución del número de turistas nacionales y extranjeros en los meses de temporada alta, enero y febrero, desde el año 1986 hasta 2013, mientras que para Benidorm la serie de referencia ha sido la evolución de las pernoctaciones de turistas en hoteles en desde el año 1988 hasta 2013. Se trata de las series más amplias y significativas disponibles, aunque presentan limitaciones evidentes: en Balneario Camboriú sólo se recoge la actividad en la temporada alta y en Benidorm la propia de los establecimientos hoteleros, excluyendo otras modalidades de alojamiento turístico. No obstante, ambas series se consideran una aproximación válida para los objetivos de este trabajo.

\subsection{BALNEARIO CAMBORIÚ: PÉRDIDA DE FUNCIÓN TURÍSTICA Y MAYOR ESPECIALIZACIÓN RESIDENCIAL}

La evolución del número de turistas en Balneario Camboriú diseña una curva inicialmente ascendiente, aunque se observan variaciones acusadas derivadas de inestabilidades económicas. Según la figura adjunta, se identifican 6 etapas principales. 
Figura 2. Periodos y factores condicionantes de la evolución turística reciente de Balneario Camboriú (1986-2013).

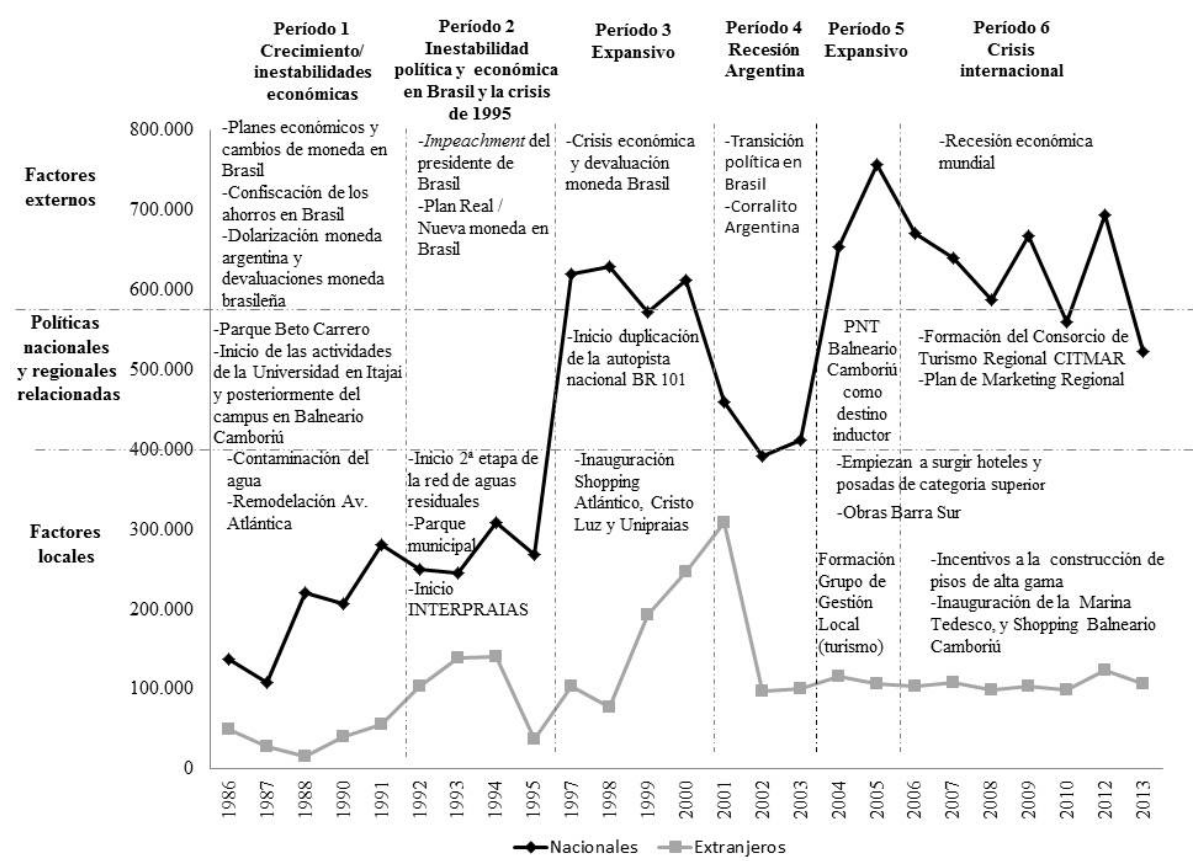

Fuente: Elaboración propia a partir de Starke Lee, 1998; Peluso e Silva y Philippi Jr., 2002; Minella, et al., 1999 y SANTUR.

* Periodo 1: Crecimiento/inestabilidades económicas (1986-1991). La década de los años ochenta se caracteriza por diversos problemas económicos en países de América Latina. Asimismo existe una tendencia al crecimiento debido a que la disminución de un mercado es compensada por el aumento de otro. La devaluación que ocurre en Brasil y la dolarización de la moneda argentina hacen que la demanda argentina compense el descenso de la demanda nacional. En esta fase ocurre la inauguración del Parque Beto Carrero (en Penha), el mayor parque temático de América Latina, que viene a impactar de manera positiva en los flujos de turistas. Esta fase es marcada por un gran crecimiento del sector inmobiliario, considerado una inversión segura frente a las crisis económicas y cambios en la moneda. Además, la apertura de la universidad en el municipio vecino de Itajaí, con un campus en Balneario Camboriú viene a fomentar del mercado de alquiler de inmuebles. En esta fase se renueva la avenida costanera de la Playa Central, la principal playa de la ciudad y que empieza a presentar problemas de contaminación del agua. Asimismo, desde el punto de vista inmobiliario es el área más valorada de la ciudad. 
* Periodo 2: Inestabilidad política y económica en Brasil y la crisis de 1995 (1992-1995). A pesar de las dificultades políticas y económicas, al igual que en la fase anterior, la variación entre la demanda nacional y extranjera vienen a garantizar el crecimiento. Excepto en 1995 cuando los efectos de la crisis afectan a diversos países y la paridad de la moneda brasileña al dólar generan la disminución de la demanda internacional. Entre 1992 y 1995 hay un descenso en el porcentaje de turistas que utiliza hoteles, bajando de 30,65\% hasta $12,73 \%$. La estancia media de los turistas en todos los medios de hospedaje es de aproximadamente 14 días. En esta fase se inicia la pavimentación de la carretera INTERPRAIAS que da acceso las playas al sur del municipio consideradas Agrestes, y que en un futuro, fomentará el desarrollo inmobiliario de este espacio. En el ámbito urbanístico se crea el Parque Natural Municipal Raimundo Gonçalez Malta, ubicado en la zona periférica de la ciudad y se inicia la segunda etapa de la red de recolección de aguas residuales.

* Periodo 3: Expansivo (1997-2000). Se observa un gran crecimiento del número de turistas en el periodo de 1995-1997. Es importante destacar la ruptura de la serie que no considera la variación del año anterior y que el porcentaje se acentúa en su apreciación gráfica debido a la disminución que ocurre del año 1994 a 1995. El crecimiento de la demanda se puede relacionar con la estabilidad económica en Brasil debido al nuevo plan económico. Asimismo, en 1999, la devaluación de la moneda retrae el mercado nacional e impulsa el internacional. El crecimiento está muy relacionado con el turismo residencial. El porcentaje de turistas en medios de hospedaje reglados es bajo y, en 2000 , se registra un $12,91 \%$, el porcentual más bajo de toda serie disponible. La expansión de la demanda viene acompañada del incremento de la oferta de ocio en el destino, con la inauguración del Complejo Cristo Luz, el Parque UNIPRAIAS y el Shopping Atlántico. El shopping Atlántico viene a consolidar la calle paralela a la costanera de la Playa Central como un área que concentra el comercio. El parque UNIPRAIAS contribuye a la revitalización de la zona sur de la Playa Central, a la vez que fomenta el flujo hacia la playa agreste de Laranjeiras. Al final de esta fase se concluye la carretera que da acceso a las Playas Agrestes.

* Periodo 4: Recesión Argentina. (2001-2003). Los problemas económicos en Argentina impactan de manera drástica en la demanda internacional. A partir de este momento la demanda internacional en Balneario Camboriú manifiesta un estancamiento y no vuelve a recuperarse. En esta fase hay un descenso de la ocupación hotelera, de $85 \%$ en 2001 a 56\% en 2003. Respecto a la planta hotelera del municipio, caracterizada por establecimientos de baja categoría, en esta fase se inaugura un nuevo establecimiento de hospedaje de categoría superior en la Playa dos Amores y el resort en la Playa do Buraco. Se observa el surgimiento de nuevos medios de hospedaje hacia el sur (Playas Agrestes) 
y hacia el norte de la Playa Central. En el ámbito urbanístico se inician importantes cambios en la zona sur de la Playa Central, el ensanchamiento de la playa y la construcción del muelle. Dichas obras revitalizan la zona para el turismo y fomentan la construcción de edificios residenciales.

* Periodo 5: Expansivo. (2004-2005). En esta fase, una vez superadas las inestabilidades del cambio de gobierno en Brasil, se alcanza el mayor número de turistas de la serie. Sin embargo, la estancia media que sigue una tendencia decreciente (10 días). Surgen dos nuevos establecimientos de categoría superior en la Playa do Estaleiro (una de las playas agrestes). Se advierte también una importante dinámica de desarrollo inmobiliario. Respecto a las políticas públicas relacionadas al turismo, en esta fase el municipio empieza a participar como destino inductor en el Programa de Regionalización del Turismo y en el ámbito local se forma el Grupo de Gestión Local de la competitividad del destino Balneario Camboriú, formado por representantes del sector público, privado y de la sociedad civil organizada. El grupo tiene el objetivo de debatir y establecer prioridades para el desarrollo turístico municipal.

* Periodo 6: Crisis internacional. (2006 a la actualidad). La crisis internacional reduce el número de turistas. En cuanto a la oferta hotelera, en 2007 se inaugura el primer hotel perteneciente a una cadena internacional en el municipio (Hotel Mercure). A pesar del surgimiento de nuevos establecimientos de hospedaje a partir del año 2000, también se registra el cierre de algunos hoteles en la zona de la Playa Central. Los nuevos hoteles en las playas al norte y al sur son principalmente posadas, con menor capacidad que los hoteles. Respecto a la estancia media en todos los medios de hospedaje, se alcanza el valor más bajo en 2008, de 8,8 días. En esta fase se inaugura el Balneario Camboriú Shopping, un centro comercial de mayor dimensión en el barrio dos Estados, frente a la estación de autobuses y cercano a la salida de la autopista, con vistas a diversificar la oferta de ocio. En cuanto a las acciones emprendidas por el sector público, a través de la legislación de uso y ocupación del suelo se busca incentivar nuevos medios de hospedaje de categoría superior, y se fomenta la construcción de edificios de alta gama. En la zona sur de la Playa Central se construye la Marina Tedesco, que junto a las demás obras anteriormente realizadas revaloriza los inmuebles del área. En cuanto a la gestión se constituye el Consorcio Turístico Regional CITMAR con vistas a un desarrollo turístico integrado entre los municipios de la región, y que elabora el primer Plan de Marketing. 
Figura 3. Evolución de la actividad turística en Balneario Camboriú: periodos y transformaciones territoriales.

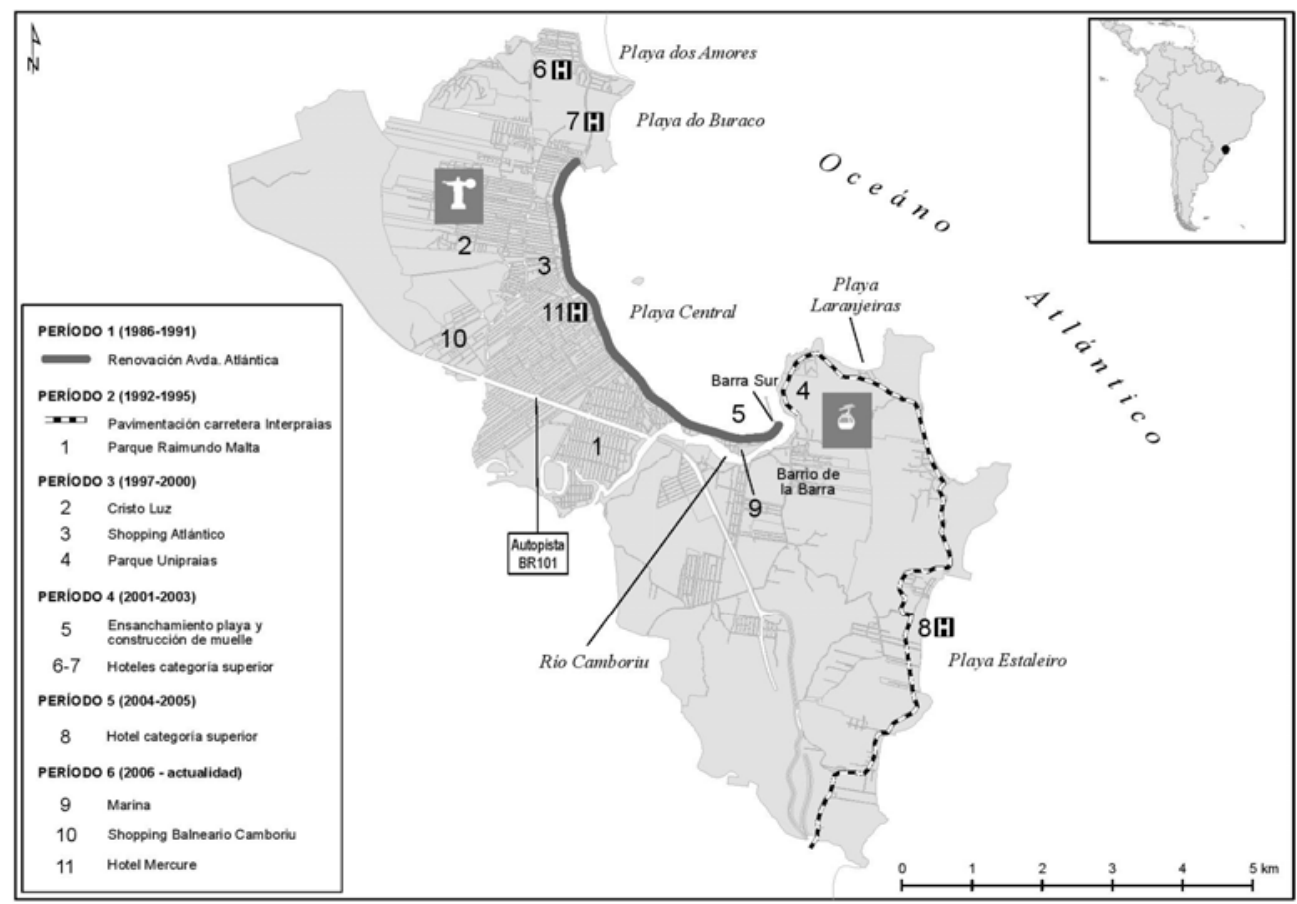

Fuente: Elaboración propia.

\subsection{BENIDORM: FASE DE MADUREZ EXTENDIDA CON UN COMPORTAMIENTO CÍCLICO}

La evolución de las pernoctaciones hoteleras en Benidorm describe la curva propia de un destino consolidado, sin variaciones de demanda muy acusadas. De acuerdo con la figura adjunta, se identifican cinco etapas fundamentales. 
Figura 4. Periodos y factores condicionantes de la evolución turística reciente de Benidorm (1988-2013).

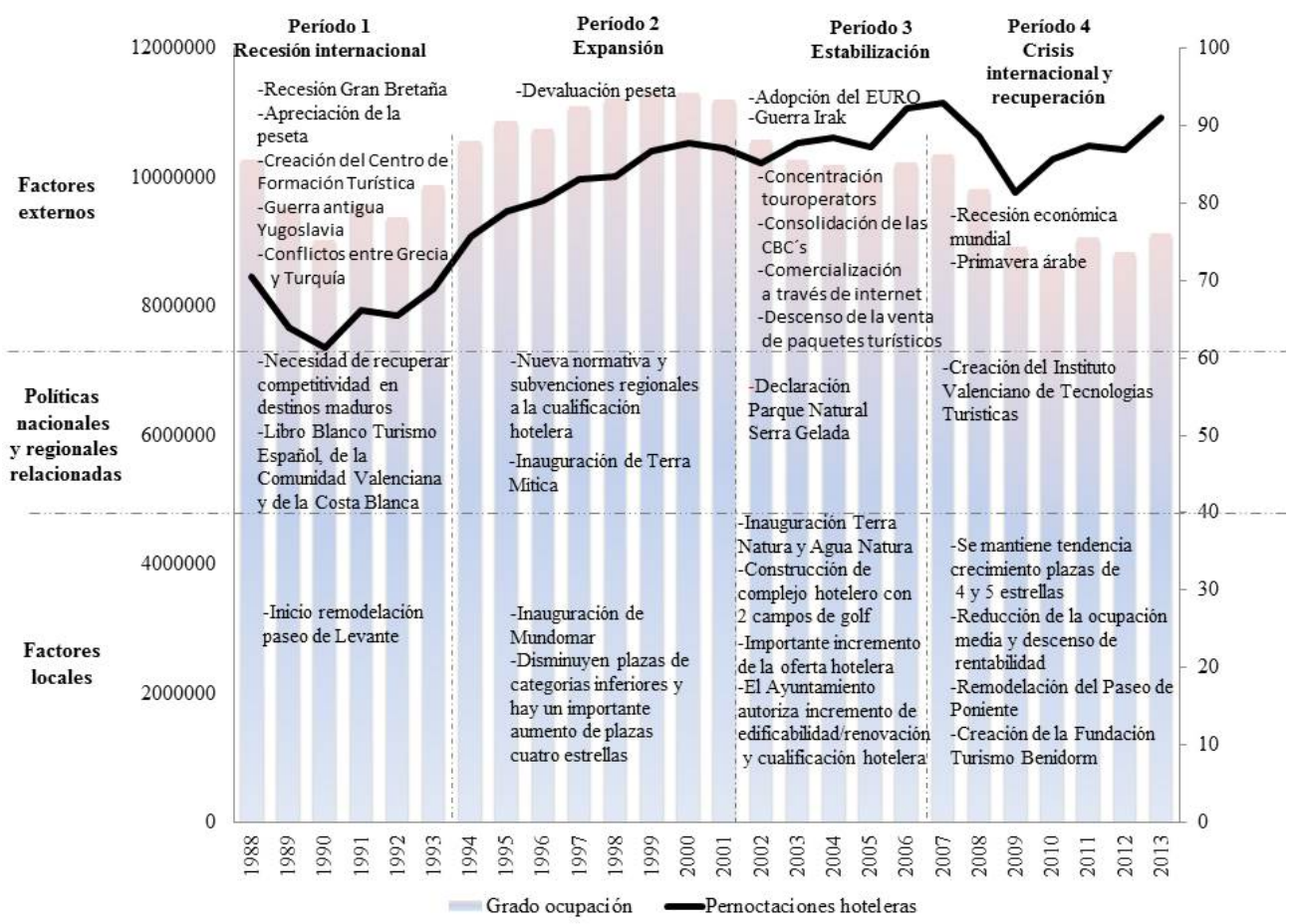

Fuente: Elaboración propia, a partir de Ivars et al. (2012; 2013) y Agencia Valenciana del Turismo.

* Periodo 1: Recesión internacional (1988-1993). La crisis del tránsito de los ochenta a los noventa se supera gracias a la devaluación de la peseta. Es una fase donde se percibe claramente la madurez del destino y se acometen medidas de renovación en la Playa de Levante (renovación del paseo marítimo) y en el centro urbano (construcción del Parque de la Aigüera, una renovación del espacio público con escasa incidencia en la actividad turística).

* Periodo 2: Expansión (1994-2001). El crecimiento de la demanda es paralelo a la cualificación de la oferta hotelera, un esfuerzo inversor privado facilitado por subvenciones de la Administración Regional de Turismo. Al final de esta etapa se produce una de las operaciones de rejuvenecimiento más importantes del destino, financiada fundamentalmente por la Administración Autonómica: la creación del parque temático Terra Mítica. Desde el punto de vista territorial, esta iniciativa rompe con el modelo urbanístico concentrado del destino para facilitar la edificación residencial extensiva en el entorno del 
parque, a la vez que crea una expectativa favorable a la creación de nuevas plazas turísticas.

* Periodo 3: Estabilización (2002-2007). El inicio del milenio viene marcado por la adopción del euro, que impide el recurso a la devaluación de la peseta como medida macroeconómica de mejora de la competitividad turística y dificulta la competencia basada en precios. Asimismo, se observan cambios estructurales en el mercado turístico como la consolidación de las compañías aéreas de bajo coste, la comercialización a través de internet y el descenso de la venta de paquetes turísticos. Continúa incrementándose la oferta de ocio del destino con la apertura de 2 nuevos parques (Terra Natura y Aqua Natura), así como 2 campos de golf con oferta hotelera en el entorno de Terra Mítica. Por otra parte, el eje de acceso al Rincón de Loix se convierte en un ámbito para la localización de nueva oferta hotelera de 4 estrellas. Dicha oferta supone el 38\% de la oferta hotelera del destino, cuando en 1993 no alcanzaba el 8\%. Desde el punto de vista de la política ambiental, la Administración Autonómica declara el Parque Natural de la Serra Gelada y su entorno litoral, figura de protección que contiene las presiones urbanísticas sobre este espacio costero y que favorece el desarrollo de la oferta de ocio basada en la naturaleza (senderismo, buceo en la Isla de Benidorm, etc.), con una demanda, todavía, minoritaria.

* Periodo 4: Crisis internacional y recuperación (2007 a la actualidad). La crisis internacional provoca una reducción de las pernoctaciones en 2008 y 2009 pero se produce una pronta recuperación de las cifras globales debido a los efectos de la denominada Primavera Árabe y la inestabilidad política del Norte de África, que desvía turistas del Norte de África a destinos españoles, y por el mantenimiento de los niveles de demanda nacional por tratarse de un destino asequible. No obstante, el grado de ocupación media anual cae al $76 \%$, muy por debajo del $94,4 \%$ alcanzado en 1999 , como consecuencia del incremento de la oferta hotelera. En esta etapa se renueva el Paseo de Poniente pero el estancamiento inmobiliario y la reducción de los presupuestos públicos ralentiza el desarrollo de nuevos proyectos, hasta el punto de paralizarse obras como el Centro Cultural, financiado por la Administración Regional, percibido como una oportunidad para el desarrollo del turismo de congresos. Desde el punto de vista de la gestión, se crea al Fundación Turismo Benidorm como órgano de gestión público-privado del turismo en la ciudad, un ente que está desarrollando interesantes iniciativas a pesar de las dificultades de funcionamiento que afronta, sobre todo desde el punto de vista de la financiación, tanto pública como privada. Por otra parte, el gobierno regional crea el Instituto Valenciano de Tecnologías Turísticas (Invat.tur), una apuesta por la innovación y el desarrollo tecnológico en el turismo con sede en Benidorm, aunque lastrado por las dificultades presupuestarias. 
Figura 5. Evolución territorial de la actividad turística en Benidorm: periodos y transformaciones territoriales.

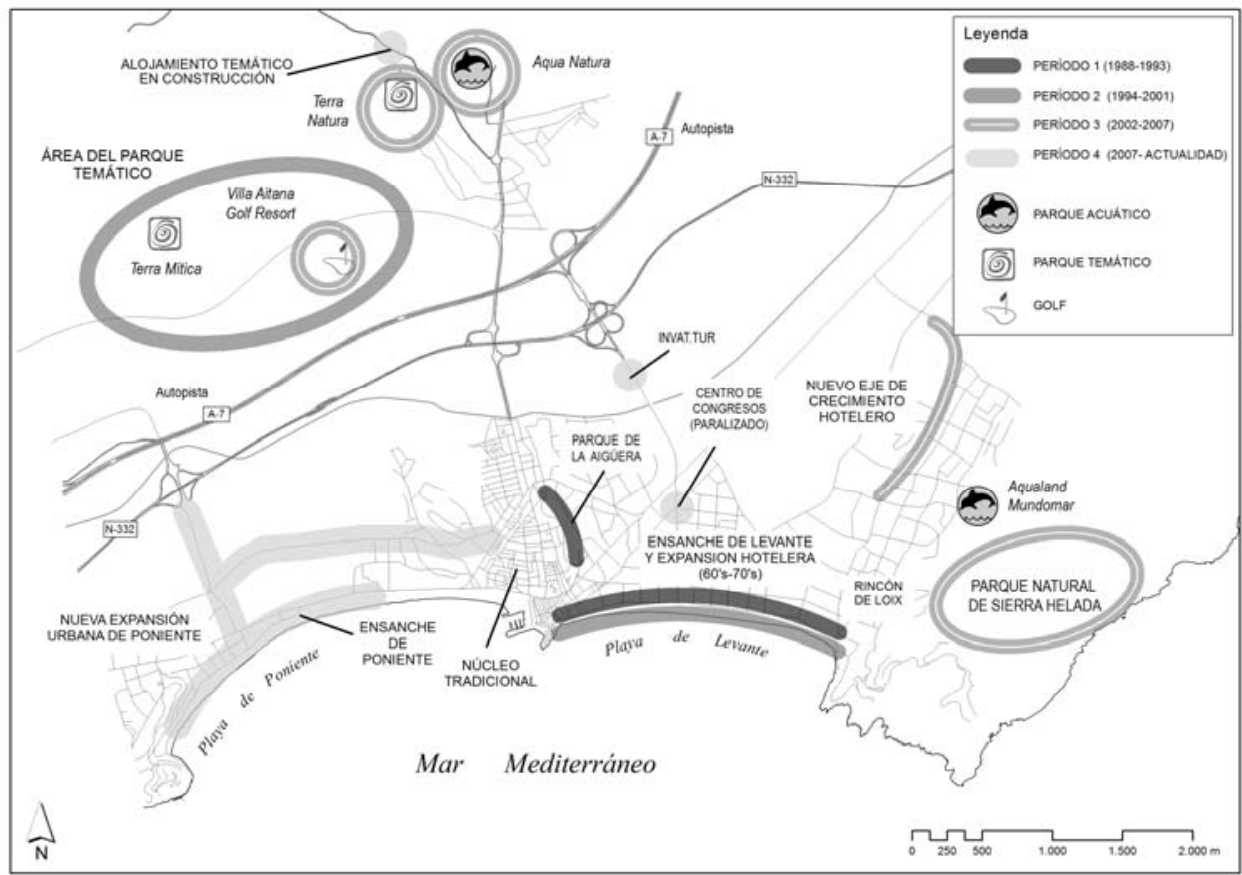

Fuente: Elaboración propia a partir de Ivars et al. (2012; 2013).

\section{CONCLUSIONES}

El análisis realizado permite establecer conclusiones en torno a dos apartados directamente conectados con los objetivos de este trabajo: la contribución a una mejor comprensión de las dinámicas de cambio en los espacios turísticos y las propuestas de mejora en el ámbito de la planificación y gestión de los destinos litorales consolidados.

Los destinos integran dinámicas turísticas y territoriales, vinculadas en buena medida a la construcción y al residencialismo propio de áreas turísticas, que difícilmente pueden explicarse con indicadores tradicionales como el número de turistas o de pernoctaciones. Se evidencia claramente que la evolución de los destinos turísticos litorales genera espacios urbanos complejos (Anton, 2014; Equipe MIT, 2005). Por esta razón, los estudios evolutivos deben incorporar diferentes variables (tanto de oferta y demanda turística como de las características físicas, sociales, económicas y ambientales del destino) y, sobre todo, una perspectiva territorial. La combinación de la perspectiva temporal y la territorial refleja más claramente las 
transformaciones de los destinos, el modelo turístico resultante y sus perspectivas de evolución futura. De lo contrario, el modelo de ciclo de vida resulta excesivamente abstracto y genérico. En este sentido, los nuevos planteamientos de la EEG incorporan una perspectiva de análisis mejor adaptada a la complejidad de los destinos.

La evolución de ambos destinos aparece marcada fundamentalmente por la ubicación geográfica, la planificación y gestión del destino, la dependencia de los dos principales mercados emisores y, de manera marcada, por la influencia de factores macroeconómicos. La dialéctica "glocal" (Milne y Ateljevic, 2001) arroja diferencias sensibles. Estas evidencias reflejan claramente el interés del análisis de la evolución de los destinos desde la perspectiva de la coevolución entre los factores micro y macro que influyen en las dinámicas del destino (Ma y Hassink, 2013).

Los cambios estructurales en el mercado turístico (consolidación de compañías de bajo coste, despaquetización, comercialización online, etc.) afectan a Benidorm mientras que son otras las dinámicas que marcan la evolución de Balneario Camboriú. Para Benidorm, los cambios en el mercado turístico actúan como un estímulo para la mejora del destino, a la vez que suponen una amenaza de pérdida de competitividad. Sin embargo, Balneario Camboriú ahonda en sus problemas estructurales (desatendiendo los efectos de los ciclos inmobiliarios que han aflorado en la crisis internacional reciente), de modo que se vislumbran conflictos que comprometen su estrategia de calidad residencial, derivados de los impactos ambientales o de los problemas de exclusión social, alejándose del modelo turístico-hotelero que aporta mayor rentabilidad económica y social. En una aproximación a la teoría de la dependencia del camino, cabría identificar trayectorias dependientes dispares: la especialización inmobiliaria para Balneario Camboriú y la persistencia de la oferta hotelera como motor de la actividad turística en Benidorm.

En el plano propositivo, la investigación realizada permite plantear una serie de recomendaciones para los destinos. En ambos casos, resulta aconsejable racionalizar las dinámicas territoriales expansivas; diversificar la oferta; mantener el posicionamiento competitivo en segmentos medios, más acordes con la realidad de los destinos que los segmentos de alto poder adquisitivo, que pueden tener cabida en iniciativas puntuales; mejorar su posicionamiento en los segmentos jóvenes como clave de evolución futura; y reforzar la comercialización conjunta con otros destinos.

En el caso de Benidorm, se proponen acciones para la mejora de la imagen del destino, todavía con excesivas connotaciones de turismo masivo, y un proyecto integral de renovación urbana basado en las ventajas de la concentración urbana, así como la definición de una estrategia competitiva, con el mayor grado de consenso posible, que evite guerras de precios y mejore los beneficios empresariales y la rentabilidad social del turismo en términos de generación de renta y empleo. La creciente asociación del modelo concentrado y hotelero de Benidorm con pautas propias de un turismo sostenible (menor consumo de suelo, gestión más eficiente de los recursos energéticos e hídricos, uso reducido de vehículos privados, etc.) (Thomson Holidays, 2010) supone una oportunidad para una estrategia que priorice 
realmente la sostenibilidad en todas sus dimensiones (ambiental, económica y sociocultural).

Por otra parte, Balneario Camboriú requiere un gran esfuerzo de gestión turística que dote al municipio de un plan estratégico elaborado mediante la participación de la sociedad local, intensifique los procesos de colaboración entre los agentes del destino y mejore el conocimiento de la actividad turística en el municipio. Desde el punto de vista urbanístico, es necesario desarrollar acciones que contengan la especulación inmobiliaria, eviten problemas de exclusión social, reduzcan los impactos ambientales (sobre todo la contaminación de las aguas de baño) y promuevan la renovación y la creación de oferta de alojamiento reglado para reimpulsar la función turística del municipio.

\section{REFERENCIAS BIBLIOGRÁFICAS}

AGARWAL, S. (2005): Global-Local Interactions in English Coastal Resorts: Theoretical Perspectives. Tourism Geographies, vol. 7, $\mathrm{n}^{0}$ 4, 351-372. DOI:10.1080/14616680500291147.

AGARWAL, S. (2002): La reconversión del turismo costero: el ciclo de vida del destino turístico costero. Annals of Tourism Research en español, vol. 4, nº1, 1-36.

AGARWAL, S. (1997): The resort cycle and seaside tourism: an assessment of its applicability and validity. Tourism Management, vol.18, $\mathrm{n}^{0} 2,65-73$. DOI:10.1016/S0261-5177(96)00102-1.

AGARWAL, S. (1994): The resort cycle revised: implications for resorts. Progress in Tourism Recreation and Hospitality Management, vol. 5, 194-208.

AGUILÓ, E.; ALEGRE, J.; y SARD, M. (2005): The persistence of the sun and sand tourism model. Tourism Management, 26, 219-231. DOI:10.1016/j.tourman.2003.11.004.

ANTON, S (2014): Rethinking mass tourism, space and place. En Wilson, J. (Ed.): The Routledge Handbook of Tourism Geographies. Londres, Routledge, 217-224.

AYALA, H., MARTÍN, R. y MASIQUES, J. (2003): El turismo de sol y playa en el Siglo XXI. En Convención de Turismo de Cuba, XXIII, Varadero. Varadero, Ministerio de Turismo.

AYUNTAMIENTO DE BENIDORM (2012): Estudio sobre hábitos turísticos, opiniones, y valoración de la oferta turística de Benidorm: verano. Benidorm, Gabinete Municipal de Sociología y Oficinas de Turismo Municipales.

BORBA CORRÊA, I. (1985): História de duas cidades: Camboriú e Balneário Camboriú. Balneario Camboriú, edición del autor.

BOSCHMA, R. y MARTIN, R. (2007): Constructing an evolutionary economic geography. Journal of Economic Geography, 7, 537-548

BOSCHMA, R. y MARTIN, R. (eds.) (2010): The handbook of evolutionary economic geography. Cheltenham, Edward Elgar

BROUDER, P. y ERIKSSON, R. H. (2013):Tourism evolution: on the synergies of tourism studies and evolutionary economic geography. Annals of Tourism Research. DOI:10.1016/j.annals.2013.07.001. 
BUTLER, R. W. (2011): Tourism area life cycle, Contemporary Tourism Reviews. Oxford, Goodfellow Publishers.

BUTLER, R. W. (2012): Mature tourist destinations: can we recapture and retain the magic. En Vera, J.F. y Rodríguez, I. (Eds.): Renovación y reestructuración de destinos turísticos en áreas Costeras: Marco de análisis, procesos, instrumentos y realidades. Valencia, Universidad de Valencia, 19-36.

BUTLER, R.W. (ed.) (2006a): The tourist area life cycle: applications and modifications, vol. I. Clevedon, Channel View.

BUTLER, R.W. (ed.) (2006b): The tourist area life cycle. Conceptual and Theoretical Issues, vol. II. Clevedon, Channel View.

CHOY, D. J. L. (1992): Life cycle models for pacific island destinations. Journal of Travel Research, 30, 26-31. DOI:10.1177/004728759203000304.

CLAVER-CORTES, E., MOLINA-AZORÍN, J. F. y PEREIRA-MOLINER, J. (2007): Competitiveness in Mass Tourism. Annals of Tourism Research, vol. 34, n ${ }^{0} 3$, 727745. DOI:10.1016/j.annals.2007.03.010.

COOPER, C.P. (1994): The Destination Life Cycle: an Update. En Seaton A. V., Jenkins C. L., Wood .R. C., Dieke P.U.C., Bennett M. M., MacLellan L.R. y Smith R. (Eds.): Tourism. The state of the art. Brisbane, Wiley, 240-346.

CONSELLERIA DE TURISMO GENERALITAT VALENCIANA, (2010): El turismo en la Comunidad Valenciana, 2010, [en línea] http://www.turisme.gva.es/opencms/opencms/turisme/es/files/pdf/observatorio/anu arios/El_Turismo_en_la_CV-2010.pdf (01-03-2011).

CORAK, S. (2006): The modification of the tourism area life cycle model for (re)inventing a destination: a case of the Opatija Riviera, Croatia. En Butler, R.W. (Ed.): The tourism area life cycle: applications and modifications, vol. 1. Clevedon, Channel View, 271-286.

DANIELSKI, M. (2009): Padrão Arquitetônico e representação social na paisagem da beira mar de Balneário Camboriú-SC. Dissertação de Mestrado, UFSC.

DEBBAGE, K. G. (1990): Oligopoly and the resort cycle in the Bahamas. Annals of Tourism Research, vol. 17, 513-527. DOI:10.1016/0160-7383(90)90024-L.

DONAIRE, J. A., (1998): La reconstrucción de los espacios turísticos: la geografía del turismo después del fordismo. Sociedad y Territorio, 28, 55-68.

DOUGLAS, N. (1997): Applying the life cycle model to Melanesia. Annals of Tourism Research, vol. 34, nº 1, 1-22. DOI:10.1016/S0160-7383(96)00011-4.

ÉQUIPE MIT (2005): Tourismes 2. Moments de lieux. Paris, Belin.

GAVIRIA, M., MIGUEL IRIBAS, J., SABBAH, F. y SANZ ARRANZ, J. R. (1977): Benidorm ciudad nueva. Madrid, Editora Nacional.

GIBSON, C. (2008): Locating geographies of tourism. Progress in Human Geography, 32(3), 407-422.

GUÍA 4 RODAS (2011): Hotéis de Balneário Camboriú, [en línea] $<$ http://viajeaqui.abril.com.br/guia4rodas/BalnearioCamboriú-camboriu/hoteis/> (02-04-2011). 
HALL, C. M. y PAGE, S. J. (2009): Progress in Tourism Management: From the geography of tourism to geographies of tourism - A review. Tourism Management, 30(1), 3-16. DOI:10.1016/j.tourman.2008.05.014.

HOVINEN, G. R. (2002): Revisiting the destination lifecycle model. Annals of Tourism Research, vol. 29, $\mathrm{n}^{0}$ 1, 209-230. DOI:10.1016/S0160-7383(01)00036-6.

IBGE (2010): Censo demográfico, [en línea] http://www.ibge.gov.br/servidor_arquivos_est/ (20-04-2011).

INE (2012): Encuesta de ocupación hotelera, [en línea] http://www.ine.es/jaxi/menu.do?type=pcaxis\&file=pcaxis\&path=\%2Ft11\%2Fe162 eoh\%2F\%2Fa2013 (15-02-2014).

INE(2011): Cifras de población y censos demográficos, [en línea] http://www.ine.es/inebmenu/mnu_cifraspob.htm (23-08-2011).

INE(2010): Encuesta de ocupación hotelera, [en línea] http://www.ine.es/jaxi/menu.do?L=0\&type=pcaxis\&path=\%2Ft11\%2Fe162eoh\&fi le=inebase (25-02-2011).

IOANNIDES, D. (1992): Tourism development agents: The Cypriot resort cycle. Annals of Tourism Research, vol. 19, 4, 711-731. DOI:10.1016/01607383(92)90063-U.

IOANNIDES, D. y DEBBAGE, K. (1998): Neo-fordism and flexible specialization in the travel industry: Dissecting the polyglot. En Ioannides, D Y Debbage, K. (Eds.): The Economic Geography of the Tourist Industry: a Supply-Side Analysis. London, Routledge Publishers, 99-122.

IVARS, J., RODRÍGUEZ, I. y VERA, J. F. (2013): The evolution of mass tourism destinations: new approaches beyond deterministic models in Benidorm (Spain). Tourism Management, 34, 184-195. DOI:10.1016/j.tourman.2012.04.00.

IVARS, J., RODRÍGUEZ, I. y VERA, J. F. (2012): La reinvención de los destinos turísticos maduros: modelos evolutivos y dinámicas turístico-territoriales. Benidorm como paradigma. En Vera, J.F. y Rodríguez, I. (Eds.): Renovación y reestructuración de destinos turísticos en áreas Costeras. Marco de análisis, procesos, instrumentos y realidades. Valencia, Universidad de Valencia, 269-296.

JOHNSTON, C. S. (2001): Shoring the foundations of the destination life cycle model, part 1: ontological and epistemological considerations. Tourism Geographies, 3 (1), 2-28. DOI:10.1080/14616680010008685.

KNOWLES y CURTIS (1999): The market viability of European mass tourist destinations: a post-stagnation life-cycle analysis. The International Journal of Tourism Research, 1, 87-96. DOI: 10.1002/(SICI)15221970(199903/04)1:2<87::AID-JTR135>3.0.CO;2-6.

LAGIEWSKI, R. M. (2006): The application of the TALC Model: a literature Survey en The tourism area life cycle. En Butler, R, W. (Ed.): Applications and modifications, vol. 1. Clevedon, Channel View, 27-50.

LUNDTORP, S. y VANHILL, S. (2001): La teoría del ciclo de vida del destino turístico: procesos de generación y estimación. Annals of Tourism Research en español, vol. 3, n 2 , 364-383. 
MA, M. Y HASSINK, R. (2013): An evolutionary perspective on tourism area development. Annals of Tourism Research, vol. 41, 89109.DOI:10.1016/j.annals.2012.12.004.

MARRERO RODRÍGUEZ, J. R. y SANTANA TURÉGANO, M. A. (2008): Competitividad y calidad en los destinos turísticos de sol y playa: el caso de las Islas Canarias. Cuadernos de Turismo, 22, 123-143.

MARTIN, R., y SUNLEY, P. (2006): Path Dependence and Regional Economic Evolution. Journal of Economic Geography, 6, no. 4, 395-437. DOI:10.1093/jeg/lbl012.

MILNE, S. y ATELJEVIC, I. (2001): Tourism, economic development and the global-local nexus: theory embracing complexity. Tourism Geographies, 3(4), 369-393. DOI:10.1080/146166800110070478.

MINELLA, A., SANTOS, C., TOMELIN, C., TOMELIN, E., BOCCARDO, F., CANANI, I., MOURA, J., CRISPIM, L., BURATTO, M., GONZÁLEZ, N., KRAUSE, R. (1999): Análise do produto Balneário Camboriu a partir de seu parque hoteleiro. Turismo Visão e Ação, vol. 1, n 2, 23-37.

MOORE, W. y WHITEHALL, P. (2005): El ciclo de vida del área turística y los modelos de cambios de régimen. Annals of Tourism Research en español, vol.7, $n^{0} 1,48-64$.

OREJA RODRÍGUEZ, J. R., PARRA-LÓPEZ, E. e YANES-ESTÉVEZ, V. (2008): The sustainability of island destination: Tourism area life cycle and teleological perspectives, the case of Tenerife. Tourism Management, 29, 53-65. DOI:10.1016/j.tourman.2007.04.007.

PAPATHEODOROU, A. (2004): Exploring the evolution of tourism resorts. Annals of Tourism Research, vol. 31, $\mathrm{n}^{\circ}$ 1, 219-237. DOI:10.1016/j.annals.2003.10.004.

PELUSO E SILVA, S. y PHILIPPI Jr, A. (2002): A importância do saneamento básico na aplicação dos princípios de cidades saudáveis: o caso de Balneário Camboriú. Em XXVIII Congreso Iberoamericano de Ingeniería Sanitaria y Ambiental. Cancún, México.

PRIESTLEY, G. y MUNDET, L. (1998): The post - stagnation phase of the resort cycle. Annals of Tourism Research, vol. 25, $n^{0} .1,85-111$. DOI:10.1016/S01607383(97)00062-5.

SANTUR (2012): Pesquisa Mercadológica Estudo da Demanda Turística Municipio de Balneario Camboriú. Florianópolis, Diretoria de Planejamento e Desenvolvimento Turístico.

SECTURBC (2012): Estudo da demanda turística. Balneário Camboriú, Departamento de Planejamento e Pesquisa.

SHAW, G. y WILLIAMS, A. M. (1996): Critical issues in tourism: a geographical perspective. UK, Blackwell.

SKALLE, M. y REIS, A. F. (2008): Crescimento urbano-turístico: traçado e permanências urbanas em Balneário Camboriu. En Actas del X Coloquio Internacional de Geocrítica, diez años de cambios en el mundo. Barcelona, Universidad de Barcelona. 
SANZ-IBÁÑEZ, C. y ANTON, S. (2014): The evolution of destinations: towards an evolutionary and relational economic geography approach. Tourism Geographies.DOI:10.1080/14616688.2014.925965.

SOARES, J. C., GANDARA, J. M. e IVARS, J. A. (2012): Indicadores para analizar la evolución del ciclo de vida de los destinos turísticos litorales. Investigaciones Turísticas, vol. 3, 19-38. DOI:http://dx.doi.org/10.14198/INTURI2012.3.02

STARKE LEE, M. (1998): Balneário Camboriú: desenvolvimento de uma cidade litorânea. Tesina de Master, Universidad de São Paulo.

STRAPP (1988): The resort cycle and second homes. Annals of Tourism Research, vol.19, 4, 752-770. DOI: 10.1016/0160-7383(88)90046-1.

THOMSON HOLIDAYS (2010): Sustainable holiday futures. [en línea] http:// communicationcentre.thomson.co.uk/ (20-06-11).

TOOMAN, L. A. (1997): Applications of the life-cycle model in tourism. Annals of Tourism Research, vol. 24, ${ }^{0}$ 1, 214-234. DOI: 10.1016/S0160-7383(96)00052-7.

TORRES, R. (2002): Cancun's tourism development from a Fordist spectrum of analysis. Tourist Studies, vol.2 (1), 87-116. DOI:10.1177/1468797602002001098.

UNWTO (2013): Panorama del turismo internacional. Edición 2013. Madrid, UNWTO.

URRY, J. (1990): The tourist gaze: leisure and travel in contemporary societies. London, Sage.

VERA, J. (coord.), López, F., Marchena, M. y Anton, S. (2011): Análisis territorial del turismo y planificación de destinos turísticos. Valencia, Tirant lo Blanch.

VIRGEN AGUILAR, C. R. (2009): El ciclo de vida de un destino turístico: Puerto Vallarta, Jalisco, México. Revista de Cultura y Turismo CULTUR, 03, 1, 1-24.

WEAVER, D. B. (2000): A broad context model of destination development scenarios. Tourism Management, 21, 217-224. DOI: 10.1016/S02615177(99)00054-0.

WILKINSON, P. F. (1996): Graphical images of the Commonwealth Caribbean: The Tourist Area Cycle of Evolution. En Harrison, L. C. y Husbands, W. (Eds.): Practicing Responsible Tourism. International case studies in tourism planning policy and development. New York, John Wiley \& sons, 16-40.

WILSON, C. M. (1999): Benidorm the truth. Alicante, Agencia Valenciana de Turismo y Ayuntamiento de Benidorm. 